\title{
ХИМИЧЕСКОЕ ИССЛЕДОВАНИЕ ТРИТЕРПЕНОВЫХ ГЛИКОЗИДОВ ЯГОД ПЛЮЩА ОБЫКНОВЕННОГО
}

\author{
(C) Г.Б. Искендеров, С.ШІ. Мусаева* \\ Азербайджанский медицинский университет, ул. Бакиханова, 22, Баку, \\ AZ1022 (Азербайджан), e-mail: musayeva_saida@mail.ru
}

\begin{abstract}
Методом тонкослойной хроматографии в экстракте ягод плюща обыкновенного (Hedera helix L.) семейства Araliaceae установлено наличие четырех тритерпеновых гликозидов, названных по мере увеличения их полярности гликозидами А, В, C, D. Методом фракционной экстракции из сырья получены две фракции: малополярные (гликозиды А и В) и полярные (гликозиды C и D). Общее количество суммы тритерпеновых гликозидов составляет $3,71 \%$. Индивидуальные гликозиды выделены из соответствующих фракций методом адсорбционной колоночной хроматографии на силикагеле. Гликозид А - состав $\mathrm{C}_{41} \mathrm{H}_{66} \mathrm{O}_{11}$, т. пл. $228-230^{\circ} \mathrm{C},[\alpha]_{D}^{20}+17,8^{\circ}$ (c 0,$5 ; 80 \%$ этанол); гликозид $\mathrm{B}$ - состав $\mathrm{C}_{41} \mathrm{H}_{66} \mathrm{O}_{12}$, т. пл. 236 $238^{\circ} \mathrm{C},[\alpha]_{D}^{20}+16,2^{\circ}\left(\mathrm{c} 0,7 ; 80 \%\right.$ этанол); гликозид $\mathrm{C}-$ состав $\mathrm{C}_{58} \mathrm{H}_{94} \mathrm{O}_{25}$, т. пл. $188-190{ }^{\circ} \mathrm{C},[\alpha]_{D}^{20}+9^{\circ}$ (с 0,$1 ; 50 \%$ этанол); гликозид $\mathrm{D}$ - состав $\mathrm{C}_{58} \mathrm{H}_{94} \mathrm{O}_{26}$, т. пл. $190-192{ }^{\circ} \mathrm{C}$, $[\alpha]_{D}^{20}+7^{\circ}$ (с 0,15; 50\% этанол). Классическими химическими методами, ИКспектроскопией, а также методом тонкослойной хроматографии установлены идентичность малополярных биозидов и химическая природа полярных тритерпеновых гликозидов. Гликозид А имеет химическое строение 3-O- $\alpha-\mathrm{L}-\mathrm{pamно-}$ пиранозил- $(1 \rightarrow 2)-\mathrm{O}-\alpha$-L-арабинопиранозид олеаноловой кислоты и оказался известным гликозидом $\beta$-хедерином. Гликозид В имеет аналогичную углеводную цепь, а в качестве агликона - хедерагенин и является $\alpha$-хедерином. Полярные гликозиды C и D представляют собой пентаозиды олеаноловой кислоты и хедерагенина соответственно, в состав углеводных цепей которых входят два моль L-арабинозы, по одному моль D-глюкозы, D-галактозы и L-рамнозы. Оба гликозида являются монодесмозидами.

Ключевые слова: Hedera helix L., ягоды, тритерпеновые гликозиды, $\alpha$-, $\beta$-хедерины, пентаозид.
\end{abstract}

\section{Введение}

Плющ обыкновенный Hedera helix L. - единственное растение семейства аралиевых Araliaceae, встречающееся в диком виде в Европе. Произрастает также на Кавказе и в Иране [1]. В Азербайджане распространен на Апшеронском полуострове и в других местах как озеленительное, декоративное растение [2].

Плющ - лазящий кустарник, образующий короткие корни - присоски. Цветки собраны в сложные зонтики. Плоды шаровидные, на растении держатся в течение года. Цветет в августе - сентябре. Плодоносит в марте - апреле [2].

Широко используется плющ в народной медицине при желудочно-кишечных заболеваниях, хроническом насморке, туберкулезе легких, болезнях печени и селезенки, мочекаменной болезни, ревматизме [1].

Препараты плюща - Бронхикум чай, Геделикс, Проспан и другие - широко используются в клинической практике при острых и хронических инфекционно-воспалительных заболеваниях органов дыхания [3]. Препараты плюща проявляют секретолитические, отхаркивающие, общеукрепляющие и тонизирующие свойства [4], а также обладают мочегонным действием [5].

Основными биологически активными веществами, обусловливающими фармакологическую актив-

Искендеров Гаибверди Баширович - заведующий кафедрой общей и токсикологической химии, профессор, доктор фармацевтических наук, e-mail:musayeva_saida@mail.ru Мусаева Саида Шамиловна - ассистент кафедры общей и токсикологической химии, e-mail: musayeva_saida@mail.ru ность лекарственных средств из плюща, являются тритерпеновые гликозиды. Вопросами выделения индивидуальных тритерпеновых гликозидов из различных видов плюща, изучения их химического состава и строения занимались исследователи многих стран [6-11], которые установили, что агликонами этих гликозидов являются в основном общеизвест-

\footnotetext{
* Автор, с которым следует вести переписку.
} 
ные олеаноловая кислота и хедерагенин. Эти гликозиды отличаются между собой только лишь по числу углеводных цепей: монодесмозиды с одной углеводной цепью и бисдесмозиды - с двумя.

Растение ядовито. Особенно ядовиты ягоды. Описаны случаи смерти детей после употребления сочных, привлекательных ягод плюща $[1,12]$. Поэтому ягоды, препараты, а также тритерпеновые гликозиды этого растения являются объектами химико-токсикологического исследования. Однако тритерпеновые гликозиды ягод плюща обыкновенного, широко распространенного в Азербайджане, не были подвергнуты химическому исследованию. Также известно, что содержание биологически активных веществ, в том числе и тритерпеновых гликозидов, может изменяться в зависимости от климатических условий и места произрастания растения. Исходя из этого изучение тритерпеновых гликозидов ягод плюща обыкновенного, произрастающего в Азербайджане, является актуальным.

Поэтому нашей целью является выделение и химическое исследование индивидуальных гликозидов ягод плюща обыкновенного.

\section{Экспериментальная часть}

Сбор сырья проводили в мае, в период полного созревания ягод. Собранные ягоды подвергали естественной сушке в тени на сквозняке, после чего измельчали до частиц размером 2-3 мм.

Изучение качественного состава тритерпеновых гликозидов сырья, доказательство индивидуальности и чистоты выделенных гликозидов, идентификацию моносахаридов, входящих в состав углеводной цепи молекулы гликозидов, проводили методом тонкослойной хроматографии на пластинках «Silufol» (Чехия) и «Sorbfil» (Россия). В качестве подвижной фазы использовали различные системы растворителей: система I - $н$-бутанол - этанол - 25\% аммиак (10:2:5); система II - хлороформ - этанол - вода (15: $15: 5)$; система III - этилацетат - изопропиловый спирт - вода (65:23:12); система IV - бензол метанол - уксусная кислота $(1: 3: 1)$. Две последние системы использовали для моносахаридов. Тритерпеновые гликозиды обнаруживали на пластинках опрыскиванием 25\%-ным спиртовым раствором фосфорновольфрамовой кислоты [13] с последующим нагреванием в течение 5-10 мин при температуре $100{ }^{\circ} \mathrm{C}$, а моносахариды - опрыскиванием орто-толуидин-салицилатом с последующим нагреванием 5-10 мин при $120{ }^{\circ} \mathrm{C}$ [14]. Температуру плавления веществ определяли на приборе Кофлера. Удельное вращение измеряли на поляриметре марки П-161. ИК-спектры веществ были сняты на спектрометре Spectrum 100 FT-IR Spectrometers (США) Г.Н. Гумбатовой (НИИ проблем судебной экспертизы, криминалистики и криминологии Министерства юстиции Азербайджана) в таблетках $\mathrm{KBr}$.

Выделение тритерпеновых гликозидов из обезжиренного петролейным эфиром сырья проводили методом фракционной экстракции: полярная фракция (гликозиды С и D) - 50\%-ным этанолом, малополярная (гликозиды А и В) - 80\%-ным этанолом. Разделение отдельных фракций тритерпеновых гликозидов на индивидуальные вещества проводили методом адсорбционной колоночной хроматографии на силикагеле (Л, 40/100), элюируя системой I и собирая элюаты фракций по 10 мл. Фракции, имеющие одинаковый состав, объединяли, растворитель упаривали досуха. Величины $\mathrm{R}_{\mathrm{f}}$ выделенных индивидуальных тритерпеновых гликозидов в системах I и II составляют: для гликозида А - 0,84 и 0,75; В - 0,81 и 0,71; C - 0,46 и 0,40; $\mathrm{D}-0,34$ и 0,29 .

Гликозид А - состав $\mathrm{C}_{41} \mathrm{H}_{66} \mathrm{O}_{11}$, мол. масса 734 , т. пл. $228-230{ }^{\circ} \mathrm{C},[\alpha]_{D}^{20}+17,8^{\circ}$ (с 0,5; $80 \%$ этанол). В ИК-спектре обнаружены полосы поглощения: 3360-3400 см-1 (ОН-группы); 1713 см$^{-1}$ (СООН-группа), $1042 \mathrm{~cm}^{-1}$ (С-O-С-группы), $1439 \mathrm{~cm}^{-1}\left(\mathrm{CH}_{3}-г\right.$ руппы).

Гликозид В - состав $\mathrm{C}_{41} \mathrm{H}_{66} \mathrm{O}_{12}$, мол. масса 750 , т. пл. $236-238^{\circ} \mathrm{C},[\alpha]_{D}^{20}+16,2^{\circ}$ (с 0,7; 80\% этанол).

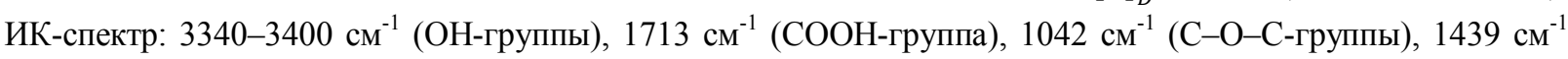
$\left(\mathrm{CH}_{3}\right.$-группы).

Гликозид $\mathbf{C}$ - состав $\mathrm{C}_{58} \mathrm{H}_{94} \mathrm{O}_{25}$, мол. масса 1190 , т. пл. $188-190{ }^{\circ} \mathrm{C},[\alpha]_{D}^{20}+9^{\circ}$ (с 0,1; 50\% этанол). ИК-спектр: 3300-3400 см-1 (ОН-группы), 1713 см$^{-1}$ (СООН-группа), 1042 см$^{-1}$ (С-О-С-группы), 1439 см${ }^{-1}$ $\left(\mathrm{CH}_{3}\right.$-группы).

Гликозид D - состав $\mathrm{C}_{58} \mathrm{H}_{94} \mathrm{O}_{26}$, мол. масса 1206 , т. пл. $190-192{ }^{\circ} \mathrm{C},[\alpha]_{D}^{20}+7^{\circ}$ (с 0,$15 ; 50 \%$ этанол). ИК-спектр аналогичен спектру гликозида С.

Установление химической природы агликонов и отдельных моносахаридов, входящих в состав углеводной цепи молекулы гликозидов, осуществили методом кислотного гидролиза $[15,16]$. Число углеводных 
цепей и место присоединения к агликону установили щелочным гидролизом [15, 17], метилированием диазометаном гликозидов [18] с последующим гидролизом, а также по ИК-спектру. Чтобы установить число моносахаридных остатков, входящих в состав углеводной цепи, провели гидролиз гликозидов в аналитических условиях [19], определяя при этом количество выделенного агликона весовым и фотометрическим [20] способами. По выходу агликона рассчитывали молекулярную массу гликозидов и, соответственно, число моносахаридных остатков, входящих в состав углеводной цепи гликозидов. Для выяснения строения углеводной цепи, последовательности расположения отдельных моносахаридов в молекуле и моносахарида, непосредственно присоединенного к агликону, применяли метод частичного гидролиза $[15,16,18]$. Установление характера гликозидных связей между отдельными моносахаридами, входящими в состав углеводной цепи молекулы тритерпеновых гликозидов, проводилось полным метилированием $[15,16]$ гликозидов с последующим кислотным гидролизом, а также периодатным окислением.

Для определения конфигурации гликозидных связей использовали метод Клайна [21], основанный на сравнении молекулярных вращений индивидуальных гликозидов и метилированных производных соответствующих моносахаридов.

\section{Результаты и обсуждения}

В экстракте ягод плюща обыкновенного методом хроматографии в тонком слое сорбента в различных системах растворителей мы установили наличие четырех тритерпеновых гликозидов, условно обозначенных по мере возрастания полярности гликозидами A, B, C, D. Методом фракционной экстракции сырья в начале 50\% этанолом выделена сумма полярных гликозидов (вещества С и D), а 80\% этанолом - сумма малополярных (вещества А и В). Общее количество суммы тритерпеновых гликозидов обеих фракций составляет 3,71\%. Хроматографированием на колонке с силикагелем из отдельной фракции суммы тритерпеновых гликозидов удалось выделить все гликозиды в индивидуальном виде. Содержание отдельных гликозидов составляет: гликозид А - 1,21\%; В - 1,35\%; C - 0,64\%; D - 0,51\%.

Результаты проведенных экспериментальных исследований по химическому изучению вышеуказанных тритерпеновых гликозидов показали, что гликозид А является биозидом олеаноловой кислоты, в состав углеводной цепи которого входят по одной молекуле L-рамнозы и L-арабинозы. Этот гликозид имеет следующее химическое строение: 3-O- $\alpha$-L-рамнопиранозил- $(1 \rightarrow 2)-\mathrm{O}-\alpha-\mathrm{L}$-арабинопиранозид олеаноловой кислоты и является известным гликозидом $\beta$-хедерином ( $\beta$-гедерином), выделенным впервые из растения рода плющ Р. Чеше и соавт. [6].

Гликозид В также является биозидом, однако в качестве агликона содержит хедерагенин. Углеводная цепь данного гликозида имеет аналогичные набор и последовательность расположения моносахаридов, как и у гликозида А. По химическому строению гликозид В идентичен $\alpha$-хедерину ( $\alpha$-гедерину), выделенному впервые также Р. Чеше и соавт. [6].

Как показали результаты химического исследования гликозида С, он является пентаозидом олеаноловой кислоты, в состав углеводной цепи молекулы которого входят по одной молекуле L-paмнозы, D-глюкозы, D-галактозы и две молекулы L-арабинозы. Причем все моносахариды связаны между собой и образуют одну углеводную цепь по гидроксилу в положении три молекулы олеаноловой кислоты. Таким образом, гликозид С отличается по составу углеводной цепи от других известных монодесмозидных гликозидов плюща. Следует отметить, что основу молекулы гликозида С составляет $\beta$-хедерин, у которого в углеводную цепь дополнительно включены три остатка моносахаридов (L-арабиноза, D-глюкоза, D-галактоза).

Гликозид D имеет аналогичный состав углеводной цепи, как и у гликозида C, лишь с той разницей, что агликоном является хедерагенин.

Уместно будет отметить, что исследователям [11] удалось выделить из плодов плюща обыкновенного шесть тритерпеновых гликозидов, двое из них оказались новыми бисдесмозидами, для которых установлено полное химическое строение. В отличие от этих новых бисдесмозидов [11], являющихся тетраозидами хедерагенина и олеаноловой кислоты, гликозиды С и D являются монодесмозидами и представляют собой пентаозиды вышеназванных агликонов.

Исследования по изучению полного химического строения гликозидов С и D продолжаются.

\section{Выводы}

1. В экстракте ягод плюща обыкновенного методом тонкослойной хроматографии установлено наличие четыре тритерпеновых гликозидов, условно названных по мере увеличения их полярности гликозидами A, B, C, D.

2. Методами фракционной экстракции и адсорбционной колоночной хроматографии на силикагеле эти гликозиды выделены в индивидуальном виде. 
3. Малополярные гликозиды А и В представляют собой биозиды и являются известными гликозидами - $\beta$-хедерином и $\alpha$-хедерином соответственно.

4. Полярные гликозиды С и D представляют собой пентаозиды олеаноловой кислоты и хедерагенина соответственно и являются монодесмозидами, содержащими по одному остатку L-рамнозы, D-глюкозы, D-галактозы и два остатка L-арабинозы.

\section{Список литературы}

1. Зузук Б.М., Куцик Р.В., Зузук Л.И. Плющ вьющийся Hedera helix L. // Провизор. 2003. №11. С. 26-29.

2. Флора Азербайджана. Баку. 1955. Т. 6. С. 356

3. Зузук Б.М., Куцик Р.В., Зузук Л.И. Плющ вьющийся Hedera helix L. // Провизор. 2003. №12. С. 13-14.

4. Смычков В.Ф. Фармакология сапонинов плюща колхидского // Здравоохранение Белоруссии. 1979. №4. C. $26-28$

5. Оруджева К.Ф., Абдуллаев Р.А. Влияние суммы сапонинов плюща Пастухова на мочеотделение // Азербайджанский медицинский журнал. 1983. №7. С. 49-52.

6. Tschesche R., Schmidt W., Wulff G. Reindarstellung und Strukturermittlung der Saponine des Efeus (Hedera helix L.) // Zeitschrift für Naturforschung, B. 1965. Bd. 20, N7. S. 708-709.

7. Искендеров Г.Б. Тритерпеновые гликозиды Hedera pastuchovii // Фармация. 1971. №4. С. 27-30.

8. Деканосидзе Г.Е. Исследование тритерпеновых гликозидов представителей рода Hedera, произрастающих в Грузии : автореф. дис. ... канд. фарм. наук. Тбилиси, 1972. 20 с.

9. Гришковец В.И., Лолойко А.А., Шашков А.С., Чирва В.Я. Тритерпеновые гликозиды Hedera taurica. VI. Строение хедерозидов $\mathrm{G}, \mathrm{H}_{1}, \mathrm{H}_{2}$ и I из ягод плюща крымского // Химия природных соединений. 1990. №6. C. $779-783$.

10. Яковишин Л.А., Гришковец В.И., Жолудь И.А. Тритерпеновые гликозиды лекарственного препарата «Гедерин» // Методы и объекты химического анализа. 2011. Т. 6, №2. С. 88-92.

11. Bedir E., Kirmizipekmez H., Sticher O., Calis I. Triterpene saponins from the fruits of Hedera helix // Phytochemistry. 2000. Vol. 53, N8. Pp. 905-909.

12. Dökmeci İ., Dökmeci A.H. Toksikoloji zehirlenmelerde tanı ve tedavi: 4. Baskı, yeniden düzenlenmiş. İstanbul, 2005. S. 561.

13. Патхуллаева М., Мжельская Л.Г., Абубакиров Н.К. Тритерпеновые гликозиды Ladyginia bucharica II. Строение ладыгинозидов А и В // Химия природных соединений. 1972. №4. С. 466.

14. Сасмаков С.А., Путиева Ж.М., Качала В.В., Саатов 3., Шашков А.С. Тритерпеновые гликозиды Zygophyllum eichwaldii. II. Строение зигоэйхвалозида I // Химия природных соединений. 2001. №4. С. 294-296.

15. Мшвилдадзе В.Д., Деканосидзе Г.Е., Шашков А.С., Кемертелидзе Э.П. Минорные гликозиды Hedera colchica. Строение хедераколхизидов $\mathrm{A}^{1}$ и С // Биоорганическая химия. 1993. Т.19, №10. С. 1001-1007.

16. Ходаков Г.В. Тритерпеновые и стероидные гликозиды рода Melilotus и их генины. VI. Мелилотозид А 2 и адзукисапонин V из корней Melilotus tauricus // Химия природных соединений. 2012. №6. С. 906-907.

17. Искендеров Д.А., Исаев И.М., Исаев М.И. Тритерпеновые гликозиды Astragalus и их генины. LXXXII. Цикломакрозид В - новый гликозид // Химия природных соединений. 2009. №4. С. 434-436.

18. Гришковец В.И., Стригунов В.С., Шашков А.С., Чирва В.Я. Тритерпеновые гликозиды Tetrapanax papyriferum. I. Выделение и установление строения гликозидов ST- $\mathrm{H}_{2}$ и $\mathrm{ST}-\mathrm{I}_{2}$ из коры стеблей тетрапанакса бумагоносного // Химия природных соединений. 2001. №2. С. 147-150.

19. Абубакиров Н.К., Аманмурадов К. Тритерпеновый гликозид вакарозид из тысячеголова посевного // Журнал общей химии. 1964. Т. 34, №5. С. 1661-1665.

20. Искендеров Г.Б., Исламов Г.Р. Определение тритерпенового сапонина Cyclamen elegans в крови и моче // Фармацевтический журнал. 2009. №3. С. 23-26.

21. Klyne W. Optical Rotation // Determination of Organic Structures by Physical Methods. New-York, 1955. Vol. 1. Pp. $73-130$.

Поступило в редакичию 20 января 2015 г.

После переработки 10 апреля 2015 г. 


\section{Iskenderov G.B., Musayeva S.Sh.* CHEMICAL INVESTIGATION OF TRITERPENE GLYCOSIDES OF BERRIES OF COMMON IVY}

Azerbaijan Medical University, ul. Bakikhanova, 22, Baku, AZ1022 (Azerbaijan),e-mail: musayeva_saida@mail.ru

Was found the presence of four triterpene glycosides named with increasing of their polarity as glycosides A, B, C, D by thin layer chromatography in the extract of berries of common ivy (Hedera helix L.) of the family Araliaceae. Using the method of fractional extraction from raw material are obtained two fractions: low polar (glycosides A and B) and polar (glycosides $\mathrm{C}$ and D). Total number of sums triterpene glycosides is 3,71\%. Individual glycoside were isolated from respective fractions by adsorption column chromatography on silica gel. Glycoside $\mathrm{A}-$ composition $\mathrm{C}_{41} \mathrm{H}_{66} \mathrm{O}_{11}$, M.P. $228-230^{\circ} \mathrm{C},[\alpha]_{D}^{20}$ $+17,8^{\circ}$ (c 0,$5 ; 80 \%$ ethanol); glycoside $\mathrm{B}$ - composition $\mathrm{C}_{41} \mathrm{H}_{66} \mathrm{O}_{12}$, M.P. $236-238^{\circ} \mathrm{C},[\alpha]_{D}^{20}+16,2^{\circ}$ (c 0,7; 80\% ethanol); glycoside $\mathrm{C}$ - composition $\mathrm{C}_{58} \mathrm{H}_{94} \mathrm{O}_{25}$, M.P. $188-190^{\circ} \mathrm{C},[\alpha]_{D}^{20}+9^{\circ}$ (c 0,$1 ; 50 \%$ ethanol); glycoside $\mathrm{D}$ - composition $\mathrm{C}_{58} \mathrm{H}_{94} \mathrm{O}_{26}, \mathrm{M}^{\circ}$. $190-192{ }^{\circ} \mathrm{C},[\alpha]_{D}^{20}+7^{\circ}$ (c 0,$15 ; 50 \%$ ethanol). By classical chemical methods, IR spectroscopy and thin layer chromatography is established the identity of low-polarity biosides and chemical nature of the polar triterpene glycosides. Glycoside A has the chemical structure as 3-O-alpha-L-rhamnnopyranosyl-( $1 \rightarrow 2)$-O-alpha-L-arabinopyranoside oleanolic acid and it is known glycoside $\beta$-hederin. Glycoside B has a similar carbon chain, and as aglycone contains hederagenin, was identified as $\alpha$-hederin. Polar glycosides $\mathrm{C}$ and $\mathrm{D}$ are the pentaosides of hederagenin and oleanolic acid, respectively. The carbohydrate chains include: 2 moles of L-arabinose, one mole of D-glucose, D-galactose and L-rhamnose. Both glycosides are monodesmosides.

Keywords: Hedera helix L., berries, triterpene glycosides, $\alpha$-, $\beta$-hederin, pentaoside.

\section{References}

1. Zuzuk B.M., Kucik R.V., Zuzuk L.I. Provizor, 2003, no. 11, pp. 26-29. (in Russ.).

2. Flora Azerbajdzhana. [Flora of Azerbaijan]. Baku, 1955. vol. 6, p. 356. (in Russ.).

3. Zuzuk B.M., Kucik R.V., Zuzuk L.I. Provizor, 2003, no. 12, pp. 13-14. (in Russ.).

4. Smychkov V.F. Zdravoohranenie Belorussii, 1979, no. 4, pp. 26-28. (in Russ.).

5. Orudzheva K.F., Abdullaev R.A. Azerbajdzhanskij medicinskij zhurnal, 1983, no. 7, pp. 49-52. (in Russ.).

6. Tschesche R., Schmidt W.,Wulff G. Zeitschrift für Naturforschung, B. 1965, vol. 20, no. 7, pp. 708-709.

7. Iskenderov G.B. Farmacija, 1971, no. 4, pp. 27-30. (in Russ.).

8. Dekanosidze G.E. Issledovanie triterpenovyh glikozidov predstavitelej roda Hedera, proizrastajushhih v Gruzii : avtoref. dis. ... kand. farm. nauk. [Research triterpene glycosides of the genus Hedera, growing in Georgia : author. dis. candidate of pharmaceutical sciences]. Tbilisi, 1972, 20 p. (in Russ.).

9. Grishkovec V.I., Lolojko A.A., Shashkov A.S., Chirva V.Ja. Himija prirodnyh soedinenij, 1990, no. 6, pp. $779-783$. (in Russ.).

10. Jakovishin L.A., Grishkovec V.I., Zholud' I.A. Metody i ob\#ekty himicheskogo analiza, 2011, vol. 6, no. 2, pp. 88-92. (in Russ.).

11. Bedir E., Kirmizipekmez H., Sticher O., Calis I. Phytochemistry, 2000, vol. 53, no. 8, pp. 905-909.

12. Dökmeci İ., Dökmeci A.H. Toksikoloji zehirlenmelerde tanı ve tedavi: 4. Baskl, yeniden düzenlenmiş. İstanbul, 2005, p. 561.

13. Pathullaeva M., Mzhel'skaja L.G., Abubakirov N.K. Himija prirodnyh soedinenij, 1972, no. 4. pp. 466. (in Russ.).

14. Sasmakov S.A., Putieva Zh.M., Kachala V.V., Saatov Z., Shashkov A.S. Himija prirodnyh soedinenij, 2001, no. 4, pp. 294-296. (in Russ.).

15. Mshvildadze V.D., Dekanosidze G.E., Shashkov A.S., Kemertelidze Je.P. Bioorganicheskaja himija, 1993, vol. 19, no. 10, pp. 1001-1007. (in Russ.).

16. Hodakov G.V. Himija prirodnyh soedinenij, 2012, no. 6, pp. 906-907. (in Russ.).

17. Iskenderov D.A., Isaev I.M., Isaev M.I. Himija prirodnyh soedinenij, 2009, no. 4, pp. 434-436. (in Russ.).

18. Grishkovec V.I., Strigunov V.S., Shashkov A.S., Chirva V.Ja. Himija prirodnyh soedinenij, 2001, no. 2, pp. $147-150$. (in Russ.).

19. Abubakirov N.K., Amanmuradov K. Zhurnal obshhej himii, 1964, vol. 34, no. 5, pp. 1661-1665. (in Russ.).

20. Iskenderov G.B., Islamov G.R. Farmacevticheskij zhurnal, 2009, no. 3, pp. 23-26. (in Russ.).

21. Klyne W. Determination of Organic Structures by Physical Methods, New-York, 1955, vol. 1, pp. 73-130.

Received January 20, 2015

Revised April 10, 2015

\footnotetext{
* Corresponding author.
} 
